\title{
RESPIRATORY MEASUREMENTS OF 3,556 SHEFFIELD SCHOOLCHILDREN
}

\author{
BY \\ JOHN E. LUNN \\ From the Department of Preventive Medicine and Public Health, University of Sheffield
}

In the epidemiological study of respiratory disease increasing use has been made of simple tests of ventilatory capacity such as the forced vital capacity (FVC), forced expiratory volume in a specified period, usually one second $\left(\mathrm{FEV}_{1.0}\right)$, and the peak expiratory flow rate (PFR). Most of these studies have been carried out in adults, for whom there are numerous series of data indicating ranges of performance in health and disease. There is relatively little information relating to children. Strang (1959) presented normal values for FVC and FEV $_{1.0}$ in 418 boys and girls aged 7 to 18 years, coming from "a good residential area of Newcastleupon-Tyne". Lyons, Tanner, and Picco (1960) presented normal values for FVC and $F F_{1.0}$ in 1,163 boys and girls aged 6 to 14 years coming from a "predominantly middle class" background in New York.

Neither of these studies provided sufficient standards for use in an investigation started in Sheffield concerning the relationship between the respiratory disease pattern of schoolchildren and their environment. The present investigation is intended to fill this gap and is based on an examination of 3,556 children aged 4 to 11 years, providing over 250 boys and 250 girls in each of the years 6 to 10. The results are presented in a form which, it is hoped, will be convenient for both epidemiological and clinical use.

\section{MeTHODS}

All the available children, irrespective of their history of past illnesses, in eighteen infant and junior schools in the city were examined between January and September, 1964. Twelve of the schools serve pre-war or post-war local authority housing estates, and six serve areas where the children, for the most part, live in rented or owner-occupied 19th century sub-standard terrace houses. The social class distribution by fathers' occupation of a sample of 498 children taken from these schools in 1963 was as follows:

\begin{tabular}{|c|c|c|c|c|}
\hline & Social Class & & \multicolumn{2}{|c|}{ Percentage } \\
\hline I & Professional, etc. & $\cdots$ & & 0.0 \\
\hline II & Intermediate & .. & $\cdots$ & $4 \cdot 2$ \\
\hline III & Skilled & $\ldots$ & .. & $66 \cdot 0$ \\
\hline IV & Partly Skilled . . & .. & • & $15 \cdot 4$ \\
\hline $\mathbf{V}$ & Unskilled & $\ldots$ & .. & $14 \cdot 4$ \\
\hline
\end{tabular}

Each child was weighed and measured in ordinary indoor clothing without shoes and jackets, the heights being recorded to the nearest $0.25 \mathrm{~cm}$. and the weights to the nearest $0.05 \mathrm{~kg}$.

The tests of ventilatory capacity were obtained with a Poulton spirometer fitted with a batteryoperated transistorized timer and a Wright peak flow meter. Both these pieces of equipment are light and easily portable. The direct reading Poulton spirometer was selected in preference to one giving a trace because this eliminates any error in interpretation of the record and because the instrument is very simply calibrated. The ability to make such a check on uniformity of behaviour is an important attribute when collecting data from different schools on separate occasions. The McKesson Vitalor, which gives traces, was used in a pilot study designed to select the most appropriate interval for the FEV. Most investigators, including Strang and Lyons, have preferred $1.0 \mathrm{sec}$., although some have used shorter intervals, such as $\mathbf{0 . 7 5} \mathrm{sec}$. In many of the younger school children it was found that by $1.0 \mathrm{sec}$. the trace was reaching its asymptote, and the FEV reading was therefore very near to the FVC. As a result of the pilot investigation an interval of 0.75 sec. was chosen. Despite this the mean FEV percentage, the ratio of the $\mathrm{FEV}_{\mathbf{0 . 7 5}}$ to the FVC, was 86.0 per cent. in boys of height $100-115 \mathrm{~cm}$., 
falling to 80.6 per cent. in those over $140 \mathrm{~cm}$. The equivalent percentages for girls were 87.5 and 84.5 respectively. Strang (1959), using an interval of 1.0 sec. for FEV, obtained figures of 84.6 per cent. for boys and 88.6 per cent. for girls, while Lyons and others (1960), using the same interval, gave a minimum of 86.4 per cent. in their series of 1,163 children. It is possible that both investigators were measuring something approaching a vital capacity in their smaller children, and that even in the Sheffield group a still shorter interval, such as $\mathbf{0 . 5}$ sec., might have been used.

When recording ventilatory measurements, Strang (1959) used the mean of the best three readings following a number of practice attempts, while Lyons and others (1960) used the best of two readings providing that these varied by no more than $150 \mathrm{cc}$. Both these workers traced their readings on revolving drums. For the Sheffield children the best of five readings was used throughout. The reason for adopting this procedure was that the younger children often required explanations and practice. Once they achieved a good reading they frequently lost interest and failed to repeat it. Alternatively these young children, having stood in a queue and watched other children perform, sometimes gave their best reading first and failed to equal it in subsequent attempts. In children aged 6 years or over it was usual to get three or four good readings out of five, but in the youngest groups one or two good readings out of five were the rule. Forced vital capacities and forced expiratory volumes are corrected to body temperature.

The repeatability of results obtained with the Poulton spirometer and Wright peak flow meter, working with a fairly rapid turnover of children on school premises, was tested by repeated examination of 83 boys and 90 girls in the age range 9 yrs 6 mths to 11 yrs $3 \mathrm{mths}$ for twelve weekly occasions throughout one term. In spite of absences it proved possible to get eight or more readings for over 90 per cent. of the children. The mean coefficients of variation for FVC, FEV $_{0.75}$, and PFR were $3 \cdot 5,3 \cdot 9$, and $7 \cdot 4$ per cent. respectively for boys and $4 \cdot 0,4 \cdot 6$, and $8 \cdot 0$ per cent. for girls. No attempt was made to correct for the growth of the children during the 12 weeks of the term, and children presenting with respiratory infections were not excluded from the series. Because of these factors the figures give a relatively pessimistic measure of the repeatability of results.

\section{RESULTS}

\section{Ages, Heights, and Weights}

Table I gives the distributions of height to age for boys and girls together with means, standard deviations, and percentiles. The class intervals of height and age permit direct comparisons with the London County Report figures (Scott, 1961). Generally speaking, the Sheffield children average

DISTRIBUTION OF HEIGHT TO AGE WITH MEANS, PERCENTILES,

\begin{tabular}{|c|c|c|c|c|c|c|c|c|c|c|c|c|c|}
\hline $\operatorname{Sex} \ldots$ & 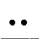 & - & $\cdots$ & $\cdots$ & \multicolumn{9}{|c|}{ Boys } \\
\hline Age (yrs) & $\cdots$ & $\cdots$ & 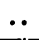 & . & $4-$ & $5-$ & 6 & $7-$ & $8-$ & 9- & $10-$ & $11-$ & Totaहि \\
\hline \multirow{2}{*}{\multicolumn{2}{|c|}{ Height (cm.) }} & & & $\begin{array}{c}<100 \\
100- \\
105- \\
110- \\
115- \\
120- \\
125- \\
130- \\
135- \\
140- \\
145- \\
150- \\
155 \text { and Over }\end{array}$ & $\begin{array}{l}6 \\
8 \\
6 \\
2\end{array}$ & $\begin{array}{r}2 \\
31 \\
48 \\
77 \\
25 \\
7 \\
1\end{array}$ & $\begin{array}{r}29 \\
78 \\
91 \\
40 \\
11 \\
2\end{array}$ & $\begin{array}{r}2 \\
26 \\
73 \\
84 \\
56 \\
15 \\
2\end{array}$ & $\begin{array}{r}1 \\
1 \\
12 \\
69 \\
120 \\
62 \\
29 \\
1\end{array}$ & $\begin{array}{r}3 \\
24 \\
74 \\
107 \\
69 \\
30 \\
5 \\
1\end{array}$ & $\begin{array}{r}1 \\
5 \\
24 \\
63 \\
85 \\
60 \\
28 \\
10 \\
1\end{array}$ & $\begin{array}{r}1 \\
15 \\
30 \\
52 \\
41 \\
19 \\
2\end{array}$ & 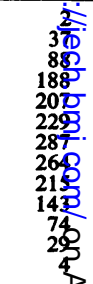 \\
\hline & & & \multicolumn{2}{|r|}{ Total } & 22 & 191 & 251 & 258 & 295 & 313 & 277 & 160 & $1,76 \underline{\underline{2}}$ \\
\hline \multicolumn{2}{|c|}{ Mean Height } & $\ldots$ & $\cdots$ & . & $108 \cdot 3$ & $110 \cdot 4$ & $116 \cdot 0$ & $121 \cdot 6$ & $127 \cdot 8$ & $132 \cdot 7$ & $137 \cdot 7$ & $143 \cdot 1$ & $N$ \\
\hline SD .. & $\cdots$ & $\cdots$ & $\cdots$ & $\cdots$ & $4 \cdot 65$ & $5 \cdot 40$ & $5 \cdot 27$ & $5 \cdot 59$ & $5 \cdot 27$ & $6 \cdot 02$ & $6 \cdot 69$ & 6.01 & \\
\hline Percentil & & & & $\begin{array}{l}\text { 5th } \\
10 \text { th } \\
25 \text { th } \\
50 \text { th } \\
75 \text { th } \\
90 \text { th } \\
95 \text { th }\end{array}$ & & $\begin{array}{l}101 \cdot 1 \\
102 \cdot 6 \\
106 \cdot 4 \\
110 \cdot 8 \\
113 \cdot 9 \\
117 \cdot 7 \\
119 \cdot 6\end{array}$ & $\begin{array}{l}107 \cdot 0 \\
109 \cdot 2 \\
112 \cdot 0 \\
115 \cdot 9 \\
119 \cdot 3 \\
123 \cdot 4 \\
125 \cdot 1\end{array}$ & $\begin{array}{l}112 \cdot 0 \\
114 \cdot 5 \\
117 \cdot 4 \\
121 \cdot 5 \\
125 \cdot 6 \\
129 \cdot 1 \\
131 \cdot 2\end{array}$ & $\begin{array}{l}120 \cdot 0 \\
121 \cdot 0 \\
124 \cdot 2 \\
127 \cdot 6 \\
131 \cdot 4 \\
135 \cdot 0 \\
137 \cdot 5\end{array}$ & $\begin{array}{l}122 \cdot 5 \\
125 \cdot 2 \\
128 \cdot 3 \\
132 \cdot 5 \\
136 \cdot 8 \\
140 \cdot 7 \\
143 \cdot 3\end{array}$ & $\begin{array}{l}126 \cdot 5 \\
129 \cdot 4 \\
133 \cdot 0 \\
137 \cdot 6 \\
142 \cdot 4 \\
146 \cdot 9 \\
149 \cdot 4\end{array}$ & $\begin{array}{l}132 \cdot 2 \\
134 \cdot 9 \\
138 \cdot 9 \\
143 \cdot 1 \\
147 \cdot 6 \\
151 \cdot 2 \\
153 \cdot 3\end{array}$ & 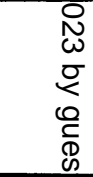 \\
\hline
\end{tabular}

Boys Overall mean height $(\bar{y})=126.9 \mathrm{~cm}$. Overall mean age $(\bar{x})=8 \cdot 46$ yrs.
Correlation coefficient $+\mathbf{0} \cdot 87$

Regression coefficient byx $=+5 \cdot 40$ 
from 1 to $2 \mathrm{~cm}$. less in height, but within each age group the height variation is similar to that in the London series. Table II gives information comparing the two series of children. The correlation between height and age is high, and for practical purposes within the age range studied the regression is linear. Correlation coefficients and regression coefficients are given in Table I.

The relationships between height and weight were similar in Sheffield and London children after correction for weight of clothing as detailed in the London County Report (Scott, 1961).

\section{Respiratory MEASUREMENTS}

It would be possible to present the ventilatory capacity data in terms of each of the single variables age, height, and weight. Alternatively, any of the three possible pairs or all three variables together could be used. In practice it is clearly simpler to use one fixed variable if this is appropriate. Strang (1959) discusses the advantage of height over age, weight, and surface area. In conformity with his work, the Sheffield data is presented in terms of height only; Table III (overleaf) shows the corresponding correlation coefficients, regression coefficients, and regression equations for FVC, $F E_{0.75}$, and PFR. Within the range of children studied here a high positive correlation is present with each measure, although it is slightly less marked with the PFR. The trends are essentially linear except at the extremes of height where the numbers of children examined were small. On the basis of these figures, therefore, there appeared to be little benefit in relating ventilatory capacity to height cubed, although Strang (1959) favours this procedure for his own series which covers an age range including the growth period associated with puberty.

TABLE II

COMPARISON OF SHEFFIELD AND LONDON CHILDREN, HEIGHT FOR AGE

\begin{tabular}{|c|c|c|c|c|c|c|c|c|c|}
\hline Age (yrs) & $\cdots$ & $\cdots$ & . & $\cdots$ & $\cdots$ & \multicolumn{2}{|r|}{6} & \multicolumn{2}{|r|}{10} \\
\hline Height (cm.) & ) & $\cdots$ & $\cdots$ & $\cdots$ & $\cdots$ & Mean & Interquartile Range & Mean & Interquartile Range \\
\hline \multirow{2}{*}{ Sex } & Boys & & $\begin{array}{l}\text { Sheffield } \\
\text { London }\end{array}$ & $\cdots$ & . & $\begin{array}{l}116 \cdot 0 \\
117 \cdot 0\end{array}$ & $\begin{array}{l}112 \cdot 0-119 \cdot 3 \\
112 \cdot 7-121 \cdot 1\end{array}$ & $\begin{array}{l}137 \cdot 7 \\
139 \cdot 1\end{array}$ & $\begin{array}{l}133 \cdot 0-142 \cdot 4 \\
134 \cdot 8-143 \cdot 6\end{array}$ \\
\hline & Girls & & $\begin{array}{l}\text { Sheffield } \\
\text { London }\end{array}$ & 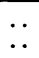 & $\therefore$ & $\begin{array}{l}115 \cdot 2 \\
116 \cdot 5\end{array}$ & $\begin{array}{l}111 \cdot 7-118 \cdot 6 \\
112 \cdot 5-121 \cdot 0\end{array}$ & $\begin{array}{l}136 \cdot 9 \\
139 \cdot 1\end{array}$ & $\begin{array}{l}132 \cdot 1-141 \cdot 7 \\
134 \cdot 3-143 \cdot 9\end{array}$ \\
\hline
\end{tabular}

I

STANDARD DEVIATIONS, REGRESSION AND CORRELATION COEFFICIENTS

\begin{tabular}{|c|c|c|c|c|c|c|c|c|}
\hline \multicolumn{9}{|c|}{ Girls } \\
\hline 4 & 5 & 6 & 7 & $8-$ & 9- & 10 & 11- & Total \\
\hline $\begin{array}{l}1 \\
9 \\
8 \\
6 \\
1\end{array}$ & $\begin{array}{r}2 \\
27 \\
84 \\
61 \\
20 \\
1 \\
1\end{array}$ & $\begin{array}{r}8 \\
25 \\
83 \\
99 \\
31 \\
6 \\
1\end{array}$ & $\begin{array}{r}5 \\
32 \\
84 \\
83 \\
39 \\
10 \\
1\end{array}$ & $\begin{array}{r}5 \\
25 \\
70 \\
104 \\
55 \\
23 \\
4\end{array}$ & $\begin{array}{r}2 \\
27 \\
101 \\
81 \\
67 \\
18 \\
4 \\
3\end{array}$ & $\begin{array}{r}3 \\
7 \\
30 \\
83 \\
83 \\
62 \\
27 \\
7 \\
3\end{array}$ & $\begin{array}{r}2 \\
7 \\
22 \\
35 \\
41 \\
28 \\
21 \\
11\end{array}$ & $\begin{array}{r}3 \\
44 \\
122 \\
187 \\
234 \\
221 \\
288 \\
252 \\
209 \\
125 \\
59 \\
31 \\
14\end{array}$ \\
\hline 25 & 196 & 253 & 254 & 286 & 303 & 305 & 167 & 1,789 \\
\hline $106 \cdot 8$ & $109 \cdot 3$ & $115 \cdot 2$ & $120 \cdot 4$ & $127 \cdot 0$ & $131 \cdot 8$ & 136.9 & $142 \cdot 2$ & \\
\hline \multirow[t]{3}{*}{$4 \cdot 76$} & 4.67 & $5 \cdot 17$ & $5 \cdot 48$ & $5 \cdot 89$ & 6.07 & 6.97 & 8.01 & \\
\hline & $\begin{array}{l}101 \cdot 3 \\
103.1 \\
106 \cdot 1 \\
109 \cdot 0 \\
112.7 \\
115.5 \\
117.9\end{array}$ & $\begin{array}{l}105 \cdot 8 \\
108.3 \\
111.7 \\
115.4 \\
118.6 \\
121.9 \\
124.0\end{array}$ & $\begin{array}{l}111 \cdot 1 \\
113 \cdot 1 \\
116 \cdot 5 \\
120 \cdot 2 \\
124 \cdot 1 \\
128 \cdot 0 \\
129 \cdot 7\end{array}$ & $\begin{array}{l}116.7 \\
119.6 \\
122.8 \\
126.9 \\
130.8 \\
134.7 \\
137.6\end{array}$ & $\begin{array}{l}122 \cdot 3 \\
124.9 \\
127.2 \\
131.2 \\
136.1 \\
139.5 \\
142.6\end{array}$ & $\begin{array}{l}125 \cdot 8 \\
128 \cdot 3 \\
132 \cdot 1 \\
136 \cdot 7 \\
141 \cdot 7 \\
146 \cdot 1 \\
148 \cdot 9\end{array}$ & $\begin{array}{l}129.4 \\
131.6 \\
136.4 \\
142.0 \\
148.1 \\
153.5 \\
156.1\end{array}$ & \\
\hline & & $\begin{array}{l}\text { Overall me } \\
\text { Overall me }\end{array}$ & $\begin{array}{l}h t(\bar{y})=1 \\
(\bar{x})=8 \cdot 4\end{array}$ & & $\begin{array}{l}\text { Correlatio } \\
\text { Regressio }\end{array}$ & $\begin{array}{l}\text { ient }+0 \\
\text { ient } b y x=\end{array}$ & & \\
\hline
\end{tabular}


TABLE III

CORRELATION COEFFICIENTS, REGRESSION COEFFICIENTS, AND REGRESSION EQUATIONS FOR FVC, FEV 0.73 , AND PFR AGAINST STANDING HEIGHT

\begin{tabular}{|c|c|c|c|c|c|}
\hline \multirow{2}{*}{ Sex } & \multirow{2}{*}{ Measurement (y) } & \multirow{2}{*}{$\underset{\text { (litres) }}{\text { Mean and SD }}$} & \multicolumn{3}{|c|}{ Correlation with Standing Height in $\mathrm{cm} .(x)$} \\
\hline & & & $r$ & byx & Regression Equation \\
\hline Boys & $\begin{array}{l}\text { FVC } \\
\text { FEV }_{\text {0.75 }} \\
\text { PFR }\end{array}$ & $\begin{array}{r}1.85 \pm 0.511 \\
1.51 \pm 0.401 \\
226 \cdot 3 \pm 62.9\end{array}$ & $\begin{array}{l}+0.90 \\
+0.87 \\
+0.73\end{array}$ & $\begin{array}{l}+0.040 \\
+0.030 \\
+3.92\end{array}$ & $\begin{array}{l}y=0.040 x-3.226 \\
y=0.030 x-2.297 \\
y=3.92 x-271.15\end{array}$ \\
\hline Girls & $\begin{array}{l}\text { FVC } \\
\text { FEV } \\
\text { PFR }\end{array}$ & $\begin{array}{r}1.69 \pm 0.490 \\
1.42 \pm 0.406 \\
217.1 \pm 66.3\end{array}$ & $\begin{array}{l}+0.91 \\
+0.88 \\
+0.77\end{array}$ & $\begin{array}{l}+0.037 \\
+0.030 \\
+4.25\end{array}$ & $\begin{array}{l}y=0.037 x-2.976 \\
y=0.030 x-2.363 \\
y=4.25 x-318.83\end{array}$ \\
\hline
\end{tabular}

Table IV (below) and Tables V and VI (opposite) relate the measures of FVC, FEV $_{0.75}$, and PFR respectively to height. The mean values of FVC are similar to those recorded by Strang (1956) and rather higher than the means recorded by Lyons and others (1960). This is shown in Fig. 1.
Examination of the data in Tables IV, V, and VI showed that the variance of each measure increased with height. For practical simplicity, therefore, and because it makes no assumptions about the form of the distribution, the ventilatory capacity data has been arranged in these Tables to show the 5th, 10th,

TABLE IV

FORCED VITAL CAPACITY (litres)

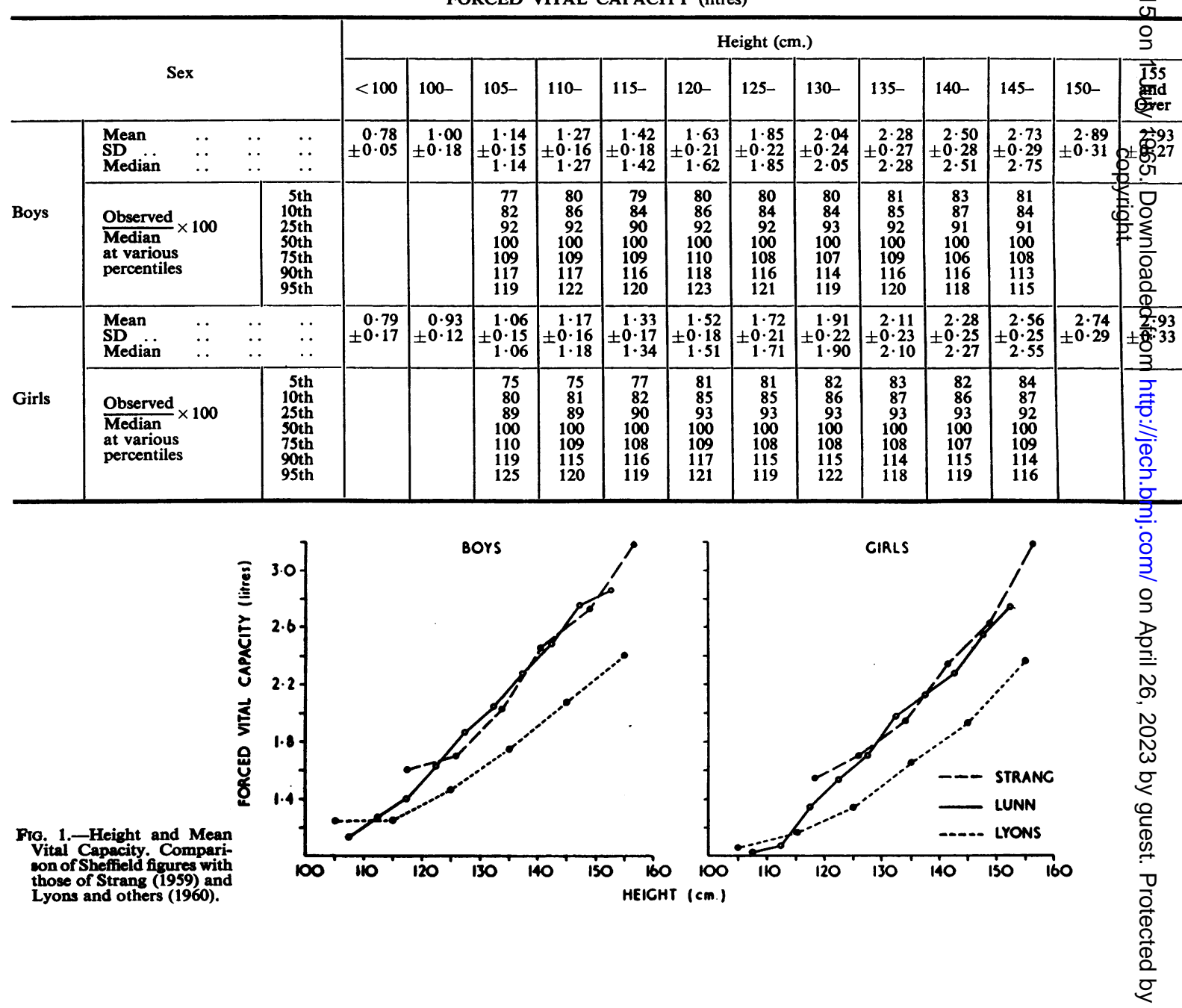


expected FVC of 1.42 litres (Table V). His ratio of actual FVC to expected FVC is

$$
\frac{1 \cdot 15}{1 \cdot 42} \times 100=81
$$

This would place him amongst the bottom 10 per cent. of children for this measure (Table IV). On the other hand, had his FVC reading been 1.60 litres, his ratio would be

$$
\frac{1 \cdot 60}{1 \cdot 42} \times 100=113
$$

and he would be amongst the top 25 per cent. (Table IV). Should the same boy be seen some considerable time later, his new height and respiratory measurements could be handled in the same way and the new ratio compared directly with the old one. For the purpose of an epidemiological study on groups, the distribution of ratios or percentile rankings of a study group can be compared with the equivalent distribution for a control group. In this context data can be used from both crosssectional and longitudinal studies.

The percentile distributions of Tables IV, V, and VI are shown diagrammatically in Figs 2 to 4 . These Figures are intended to make the data more readily usable where interpolation is required between the mid-points of the height classes used in the tabulations. Alternatively, mean heights can be calculated from the regression equations in Table III, since the differences occurring between the means and medians are of no practical importance when calculating ratios to the median within the range covered by the series.

\section{SUMMARY}

1,767 boys and 1,789 girls from eighteen Sheffield Infant and Junior schools were examined for age, height, weight, and respiratory measurements.

Mean heights averaged 1-2 cm. less than the figures for schoolchildren of the 1959 London County Report, but there was little difference in terms of weight for height.

Tables and Figures for FVC, $\mathrm{FEV}_{0.75}$, and PFR are given, permitting the prediction of mean values from standing height and permitting children to be given a ratio of actual respiratory performance to expected performance and a percentile ranking. Procedures are suggested for applying these techniques to clinical practice and epidemiological research.

I wish to thank Dr Llywelyn Roberts, Principal School Medical Officer, Dr C. H. Shaw, Deputy Principal School Medical Officer, and Dr E. G. M. Oates, Senior School Medical Officer, for their support of this project, and also the head teachers who received us into their schools and gave us every assistance.

For the collection of the data, I wish to thank Dr M. T. Lunn, Miss E. Dent, Chief School Nursing Sister, and the Nursing Sisters and Assistants of the Sheffield School Health Service who took part.

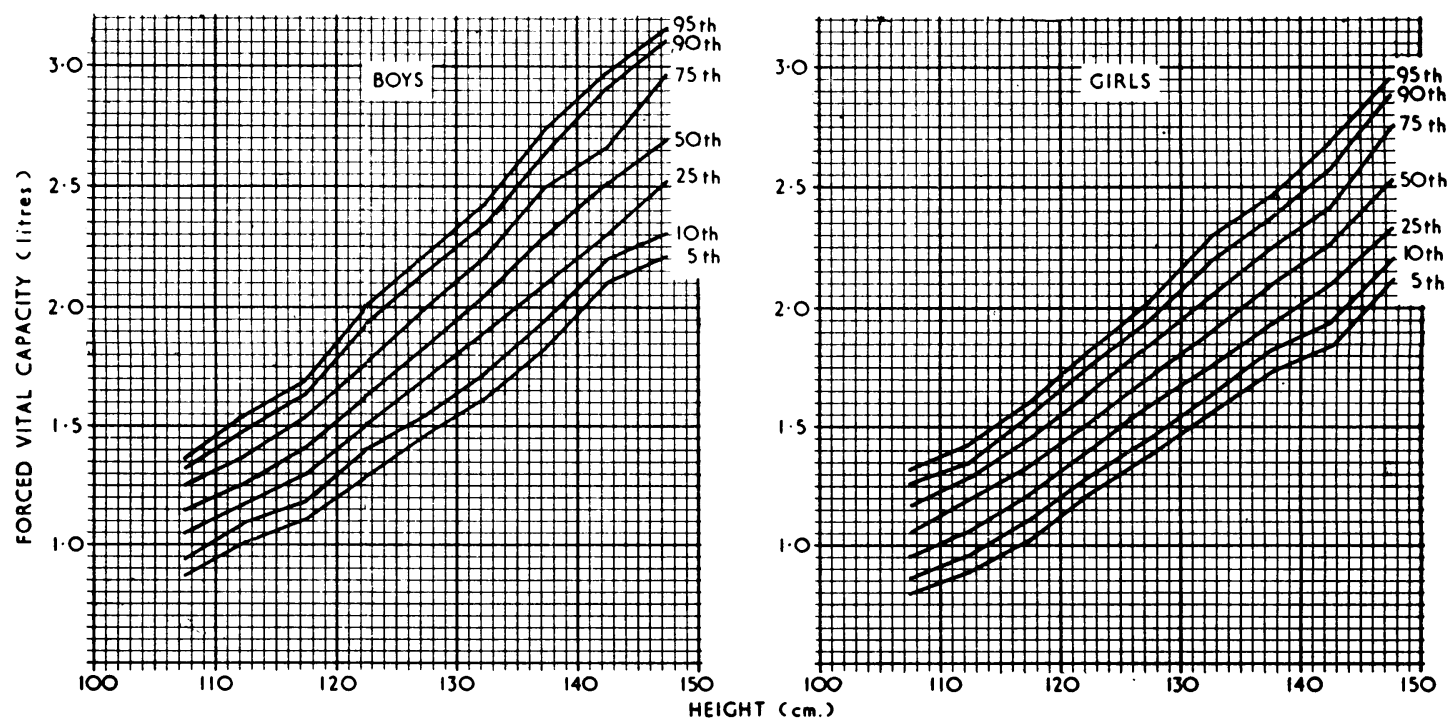

Fig. 2.-Height and Forced Vital Capacity (5th to 95th percentile). 

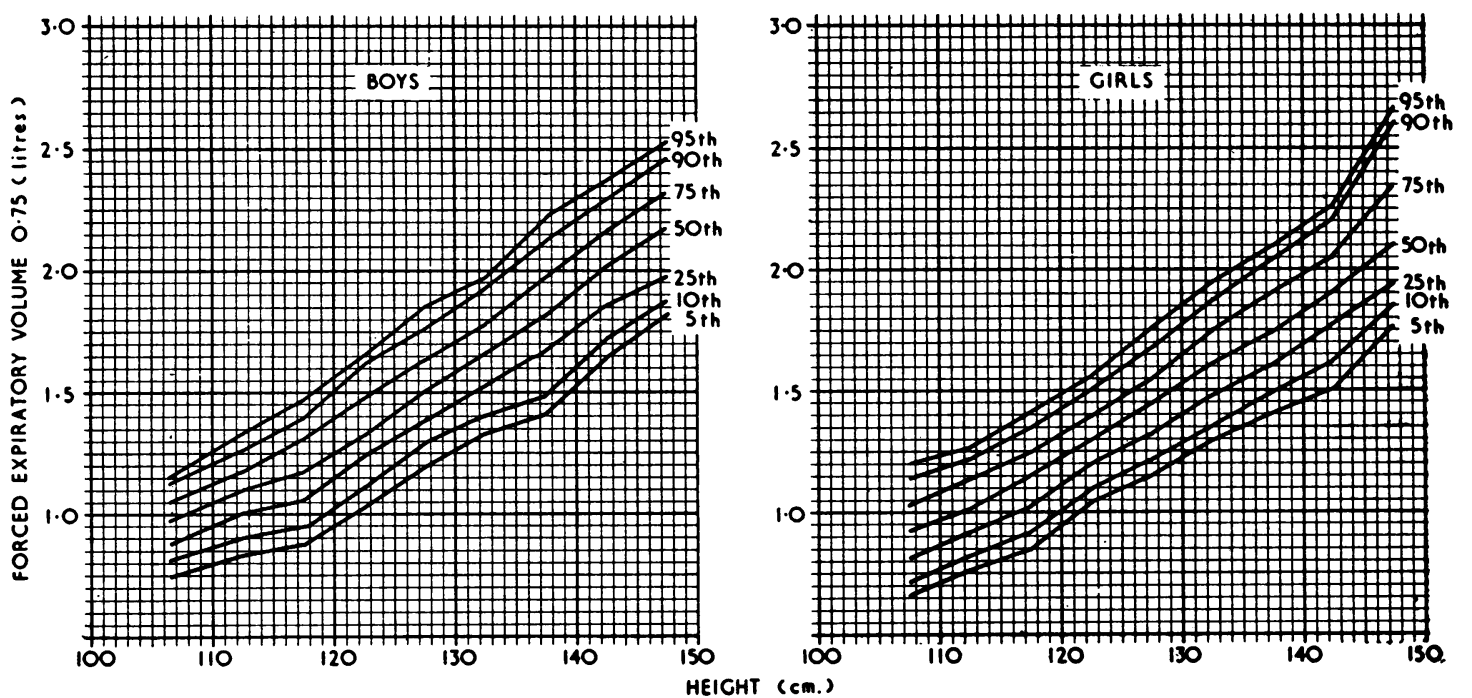

Fig. 3.-Height and Forced Expiratory Volume ${ }_{0.75}$ (5th to 95 th percentile).

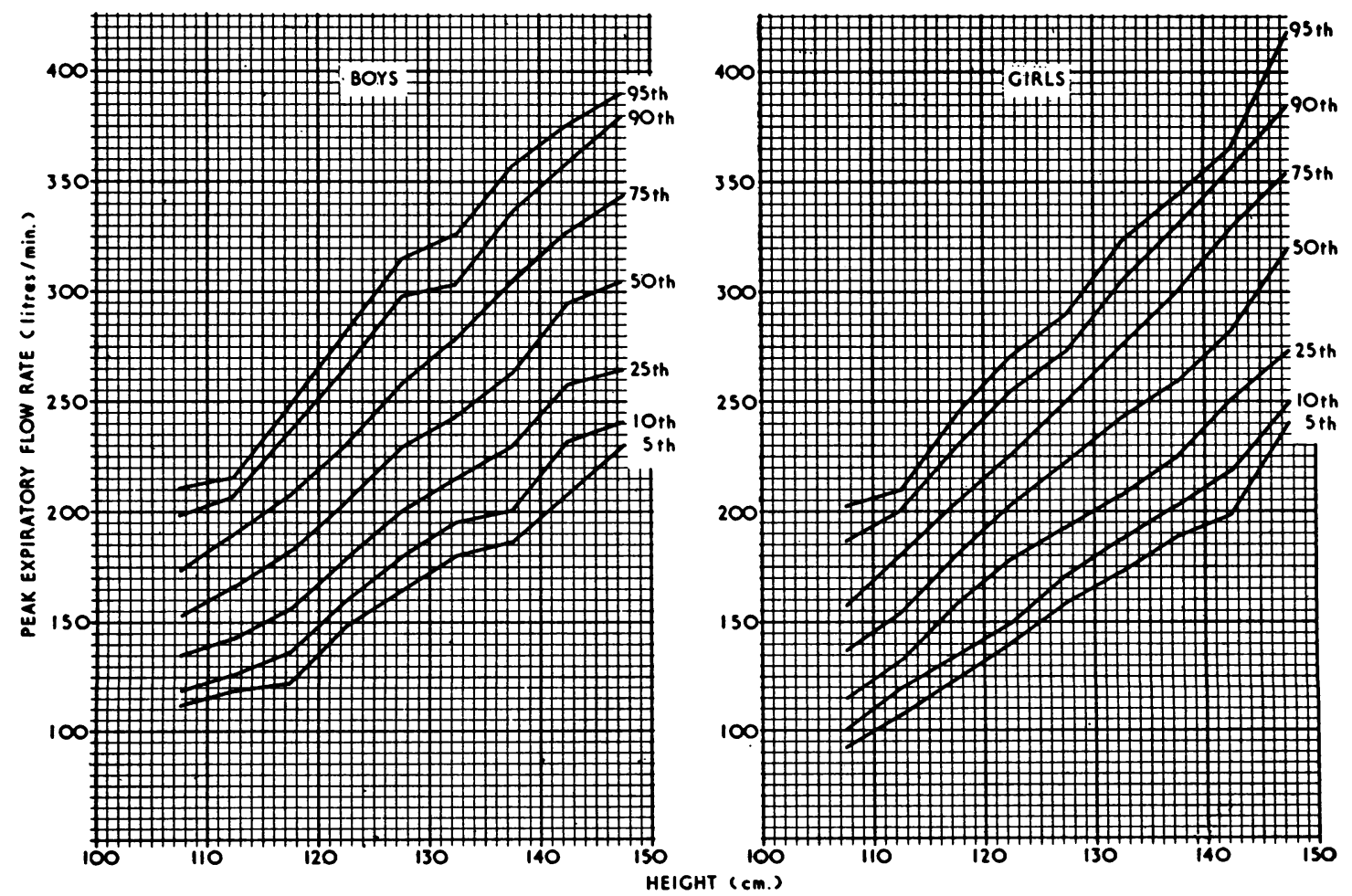

Fig. 4.-Height and Peak Expiratory Flow Rate (5th to 95th percentile). 
Prof. J. Knowelden gave valuable advice and assistance in the handling of data, and much of the hard work in this respect was done by Miss E. Frith, Miss M. Beddard, and Miss S. Rich. I also wish to thank Miss P. Ashton and Miss J. Pickering for their secretarial and clerical assistance.

Finally, I wish to thank the parents and the children themselves for their enthusiastic co-operation.

This work has been aided by a Sheffield University Tuberculosis Research Fund Grant.

\section{REFERENCES}

Kemsley, W. F. F., Billewicz, W. Z., and Thomson, A. M. (1962). Brit. J. prev. soc. Med., 16, 189.

Lyons, H. A., Tanner, R. W., and Picco, T. (1960). Amer. J. Dis. Child., 100, 196.

Scott, J. A. (1961), "Report on the Heights and Weights (and Other Measurements) of School Pupils in the County of London in 1959". London County Council Report No. 4086.

Strang, L. B. (1959). Thorax, 14, 305. 